\title{
Indicators used by farmers to design agricultural systems: a survey
}

\author{
Quentin Toffolini ${ }^{1,2,3} \cdot$ Marie-Hélène Jeuffroy ${ }^{1,2} \cdot$ Lorène Prost $^{3}$
}

Accepted: 16 September 2015 / Published online: 22 December 2015

(C) INRA and Springer-Verlag France 2015

\begin{abstract}
Agriculture is undergoing profound transformation in response to the global challenges of food security, pollution and climate change. In particular, some farmers are exploring and tentatively applying new practices based on agroecological principles. However, depending on biological regulation, these practices have uncertain results. In order to choose and monitor their changes, farmers use various indicators. In our study, we examined these indicators as they were applied in the implementation of technical changes, with a view to determining their exact nature, partly unexplored by agronomists. We held six interviews, performed a retrospective analysis of a redesign project involving five farmers and four advisors, observed collective visits at long-term field experiments, and organized a design workshop with eight farmers. We then coded the verbatim transcript in order to characterize the functions and attributes of the indicators, using the principles of grounded theory. Our results show that indicators have 22 different functions regarding the farmers' technical action, grouped into five categories. The most common functions are more learning-oriented than assessment-oriented, e.g., "adaptation-monitoring" with 92 out of the 260 statements on indicators identified, and "understanding-reinterpretation" with 107 out of 260 statements. The attributes of the indicators are predominantly visual (62\%), relative (63\%), and passive (75\%). In addition, we found that indicators used at a strategic decision level are specific, as they
\end{abstract}

Quentin Toffolini

quentin.toffolini@grignon.inra.fr

1 INRA, UMR211 Agronomie, F-78850 Thiverval-Grignon, France

2 AgroParisTech, UMR211 Agronomie, F-78850 Thiverval-Grignon, France

3 INRA, UMR 1326 LISIS, F-77454 Marne-la-Vallée, France are mostly quantified, concern large time and spatial scales, and are essentially dynamic, that is, interpreted in as trends.

Keywords Indicators · Cropping system · Design · Technical change $\cdot$ Step-by-step redesign process $\cdot$ Change monitoring . Action

\section{Introduction}

In an agroecological approach, the redesign of cropping systems to reduce dependence on synthetic inputs requires profound technical changes based on ecological principles (Wezel et al. 2014). The application of such principles in agricultural practices is strongly linked with uncertainty. In fact, it requires that agricultural practices involve new objects such as natural pest enemies, floral hedges, or cover crops intercropped with cash crops. Knowledge on these objects, i.e., their functioning and interactions with other agroecosystem components, is scarce. Furthermore, the results of actions on these objects depends heavily on local biotic and abiotic conditions (Horlings and Marsden 2011) and on long-term biological regulations. Productivity is thus highly dependent on local environmental conditions, by contrast with an approach consisting in applying inputs to reduce or overcome local biotic and abiotic constraints and thereby reducing uncertainty.

Chantre and Cardona (2014) found that farmers' changed pathways toward such agroecosystem management often stretch over long periods and involve progressive changes and learning processes. Farmers gradually improve their cropping systems by modifying some of their practices year after year (Meynard et al. 2012). During this step-by-step redesign process, they need to combine short-term decision making with the longer time scale of biological regulation. 
Driving such long-term processes requires one not only to know if the system is evolving in the targeted direction but also to adapt future actions according to the results obtained from past actions and according to feedback and to validate new combinations of techniques suited to the local environment. In such progressive technical change, farmers need to confirm the validity of new technical choices and to adjust specific practices even though the final results of these actions are not yet visible.

Agronomists have tended to resolve this dialectic between expected and actual states of an agroecosystem by means of numerous indicators (Deffontaines and Landais 1988) developed to assess the various impacts of existing or simulated practices (Bockstaller et al. 2008). Gras (1989) defined an indicator as "a variable which supplies information on other variables that are difficult to access". Girardin et al. (1999) defined indicators as variables for which a quantitative value is determined and compared to a reference value. In agriculture, indicators are usually regarded as tools for assessment focusing on the impacts of practices on an environment, which some authors map on a cause-effect relationship axis (Bockstaller et al. 2008). The choice of suitable indicators has been addressed extensively, either through the development of participative methods for building and selecting salient indicators (e.g., Barrios et al. 2006) or through the question of their accuracy (Makowski et al. 2009) and the degree of correlation between the indicator and the phenomenon to which it relates.

However, as indicators are mainly dedicated to impact assessment, their use by farmers is addressed only indirectly and only in terms of feasibility (time and money costs), relevance (is it usable alone or should it be combined with other indicators), purposes, and types of calculations and data required (Bockstaller et al. 2008). Little is known about how available indicators may efficiently serve farmers' action and learning during the transitions of their cropping system.

In fact, these indicators have mostly been designed within the paradigm of steering of agronomic systems, in which it is assumed that a manager can determine the expected effects of an action with precision. This may however not be the case with complex innovative practices designed to enhance natural processes in agroecosystems. The results measured on fields (e.g., yields) are attributed to integrated effects, but farmers may need indicators to assess other effects of an action on a system. In the agroecological approach, the need for specific indicators is sometimes acknowledged. For instance, Warner (2007) suggests that intensive rotational grazing requires that graziers "must be able to observe and interpret agroecological indicators of plant-animal interactions in their pastures". However, there is no characterization yet that would specify what such agroecological indicators are.
Our objective in this paper was therefore to identify and characterize the diversity of indicators used by farmers during progressive technical changes toward cropping systems underpinned by ecological principles. We wished to understand the different functions that these indicators fulfill in the course of the action and how this can be used by agronomists to produce new indicators specifically for these types of action. In the following section, we describe the different methods that we applied to identify these indicators and the situations and farmers that we selected. In Sect. 3, we present the functions and attributes of these indicators throughout the technical changes implemented and compare our findings to existing characterizations of indicators, either in agronomy or in other domains.

\section{Material and methods}

\subsection{Description of the four case studies}

Our research draws on four case studies consisting of semistructured interviews with farmers; a retrospective analysis of a redesign project involving farmers and their advisors; observations of farmers' visits to cropping system trials; and design workshops with groups of farmers concerning their current agronomic problems. Farmers were interviewed during visits of trials at experimental stations (in-field), at their home, or at farmers' meeting (out-of-field) (Table 1). These four case studies allowed us to identify the widest variety of indicators used in cropping system redesign as they covered the following:

1. Different levels of progress within a redesign process, relating to three main steps identified by Toffolini et al. (in revision): the choice of a technique to apply in a cropping system and the preparation of its implementation; the adaptation and monitoring of action, the stabilization of an operational method, and the confirmation of the viability of the practice; and the evaluation of the consequences of the implemented practices on the agrosystem, including elements other than those targeted by the new practices;

2. Operational, tactical, and strategic decision levels: the operational level corresponding to the adjustment and monitoring of a practice within the crop growth cycle, the tactical level corresponding to the short-term choice of techniques to apply and the strategic level corresponding to the application of one or several techniques to achieve a long-term result (e.g., reduce a disease by choosing appropriate crop succession or sowing dates); and

3. Different redesign goals and related technical changes. In the field, we accessed indicators related to visual observations and to references to a specific state of the agrosystem. Out of field, we accessed indicators related to an entire process of 
Table 1 Summaries of the case studies

\begin{tabular}{|c|c|c|c|c|}
\hline Case studies & $\begin{array}{l}1 \\
\text { Interviews with farmers }\end{array}$ & $\begin{array}{l}2 \\
\text { Analysis of a past redesign } \\
\text { project }\end{array}$ & $\begin{array}{l}3 \\
\text { Visits of system trials } \\
\text { with groups of farmers }\end{array}$ & $\begin{array}{l}4 \\
\text { Farmers meeting to } \\
\text { design a technical change }\end{array}$ \\
\hline Methods used & $\begin{array}{l}\text { Semi-structured clarifying } \\
\text { interviews }\end{array}$ & $\begin{array}{l}\text { Semi-structured interview, traces } \\
\text { analysis (meetings written } \\
\text { documents, midterm report) }\end{array}$ & Observation & Facilitation, observation \\
\hline $\begin{array}{l}\text { Number of actors } \\
\text { concerned }\end{array}$ & 6 farmers & $\begin{array}{l}5 \text { farmers, } 2 \text { facilitators, } 2 \\
\text { advisors }\end{array}$ & $\begin{array}{l}2 \text { groups of } \sim 10 \\
\text { farmers }\end{array}$ & 8 farmers, 1 advisor \\
\hline Location (farmers) & Northwestern France & Northern France & Northwestern France & Central-western France \\
\hline \multirow{3}{*}{$\begin{array}{cl}\text { Decision } & \text { Operational } \\
\text { levels } & \text { Tactical } \\
& \text { Strategic }\end{array}$} & +++ & + & +++ & - \\
\hline & ++ & ++ & + & ++ \\
\hline & + & +++ & - & ++ \\
\hline \multirow{3}{*}{$\begin{aligned} \text { Progress } & \text { Choice } \\
\text { level in } & \text { Adaptation } \\
\text { change } & \text { Consequen }\end{aligned}$} & ++ & + & ++ & ++ \\
\hline & +++ & ++ & + & + \\
\hline & + & ++ & - & - \\
\hline Main crops & $\begin{array}{l}\text { Crops: wheat, rape, barley, hemp, } \\
\text { sunflower, maize, pea, alfalfa, } \\
\text { faba bean, triticale-alfalfa } \\
\text { mixture. Livestock: cattle }\end{array}$ & $\begin{array}{l}\text { Crops: wheat, rape, barley, beet, } \\
\text { sunflower, maize, alfalfa, faba } \\
\text { bean, potato. Livestock: sheep, } \\
\text { poultry }\end{array}$ & $\begin{array}{l}\text { Crops: wheat, barley, } \\
\text { rape, maize, alfalfa, } \\
\text { pea, flax, linen }\end{array}$ & $\begin{array}{l}\text { Crops: classical arable } \\
\text { crops of the region, } \\
\text { mainly wheat, rape, } \\
\text { barley, pea, potato }\end{array}$ \\
\hline $\begin{array}{l}\text { Main goals of the } \\
\text { cropping system } \\
\text { redesign }\end{array}$ & $\begin{array}{l}\text {-improve soil structure and } \\
\text { biological activity by reducing } \\
\text { tillage; —introduce legume crops } \\
\text { to manage } \mathrm{N} \text { fertility -improve } \\
\text { weeds management by crop } \\
\text { succession and cover crops }\end{array}$ & $\begin{array}{l}\text { - decrease pesticides use by } \\
\text { implementation of integrated } \\
\text { management - improve } \\
\text { weeds management by crop } \\
\text { succession and cover crops }\end{array}$ & $\begin{array}{l}\text { - decrease fossil } \\
\text { energy use - } \\
\text { eliminate pesticides } \\
\text { use - decrease } \\
\text { greenhouse gas } \\
\text { emissions }\end{array}$ & $\begin{array}{l}\text { - decrease pesticides use } \\
\text { by diversified crop } \\
\text { succession, integrated } \\
\text { crop management, } \\
\text { mechanical weeding }\end{array}$ \\
\hline
\end{tabular}

The locations correspond to the farms (cases 1,2 and 4) or the experimental station (case 3). The signs indicate the diverse possibilities for accessing decision levels and progress levels in technical changes in the case studies, with a gradient between "-" for absence, and "+++" for predominance of the specific level in the case study

technical change and concerning diverse situations a farmer might encounter. These indicators were therefore more generic.

\subsubsection{Interviews with farmers engaged in the processes of redesigning their cropping system or who had participated in a redesign project (case studies 1 and 2)}

We interviewed 11 French farmers who were all in the process of redesigning their cropping system. Three farms had croplivestock systems and eight had only arable crops systems. The semi-structured interviews focused on specific technical changes that had taken place in recent years or were in progress or even in a preparation stage. We selected those changes that relied more broadly on natural processes. The redesign goals concerned arable crops, e.g., combination of crop practices to reduce weed pressure and insecticide use; introduction of legume crops to manage nitrogen fertility through crop succession; and improvement of soil structure and biological activity through reduced tillage and cover crops (Table 1). To minimize the possible bias due to the farmers' reconstruction of history, we focused on recent technical changes they considered most relevant to their cropping system changes. To get technical details on their actions, we asked farmers for precise details on the management of related practices and the information they collected to implement them. In addition, we consulted any available documentation they had collected on a technique.

Among the farmers interviewed, five had participated in a redesign project facilitated by an intermediary organization between research and development, between 2003 and 2012. Interviews with two advisors and two project managers from this organization allowed us to identify specific indicators that had been presented and used during the project. We paid attention to the fact that some indicators were proposed by the group facilitators, while others were identified and chosen by the farmers themselves. To complete these interviews, we analyzed a midterm report on this project (March 2007), focused on a selection of indicators related to actual practices measured on farms. On the basis of these complementary analyses, we were able to explicitly ask the farmers about their use of the indicators.

\subsubsection{Observations during visits to cropping system trials on experimental stations with groups of farmers (case study 3)}

Long-term system experiments are recognized as useful tools for agricultural system step-by-step design and for 
the production of knowledge for monitoring evolving agroecosystems (Coquil et al. 2014). We therefore monitored two different groups (Fig. 1) of farmers during visits to two cropping system trials, in order to capture knowledge exchanges about indicators. The same agronomist led a tour of the tested cropping systems at both locations. While the group was walking through the different plots, he commented on the current crops and their observed state, explained the main challenges and management difficulties, and provided a history of the past crop management of each plot. We recorded the discussions and farmers' comments. They mainly related to the situations, some visual observations made directly, and the technical choices and precise steps or modalities in crop management. These situations afforded access to indicators corresponding to what farmers looked at in fields and what such observations need to be combined with (e.g., situation characteristics, past management) in order to assess the state of a system.

\subsubsection{Design workshop with a group offarmers (case study 4)}

We organized a 1-day workshop with a group of farmers who were trying to decrease pesticide use (Table 1). As all the farmers were facing growing pressure from thistle in their fields, the workshop focused on this issue. First, the farmers were asked to present their farming and cropping systems to the group and to explain how the thistle occurred on their farm. Second, we facilitated the comparison of strategies. Third, we provided a wide diversity of written documents concerning techniques that could contribute to thistle control and the ecophysiological aspects of this species. Finally, the farmers were asked about the specific knowledge they used from the documents and how it helped them to think about possible technical changes. All discussions were recorded. We identified indicators mentioned either during the presentations of farming situations or during discussions about opportunities to implement certain techniques. This workshop enabled us to identify indicators used during the preliminary design of a technical change, thus at agronomic strategic level (Table 1).

\subsection{Data analysis: identification of functions and attributes of indicators}

We transcribed all the interviews and recorded meetings to collect all the excerpts corresponding to an indicator. We considered an indicator to be any type of information about a variable, that can either be collected in a situation or help to refer to a situation and that can correspond to the structure or the state of objects or a system of objects, as well as to fluxes within a system, or to the farmer's actions on the system. As we were particularly interested in the relation between the indicator and the action it relates to, we confirmed the identification of an indicator when it was explicitly related to an action (past or future). The subsequent treatment of data followed the principles of grounded theory (Glaser and Strauss 2009): we chose not to draw up comprehensive lists of functions or attributes beforehand so that these lists would rather be the outcome of data analysis. To define the various functions of indicators, we coded each excerpt of an indicator according to the way the farmer's action was supported. Throughout the data analysis, and after several iterations, we grouped the functions together in order to get the lowest number which would still explain the diversity. The functions were thus interpreted from farmers' discourse and described according to their point of view. Likewise, to define each indicator, we built a framework of attributes from the analysis of our data rather than $a$ priori: we collected all descriptive words that characterized the indicators and grouped them by categories to get the lowest number which would still reflect the diversity encountered. This made it possible to include relevant categories for analyzing their relation to action. These two parallel characterizations allowed us to look for links between functions and attributes of indicators.
Fig. 1 A group of farmers engaged in a process of reducing pesticide use visits a long-term cropping system experiment
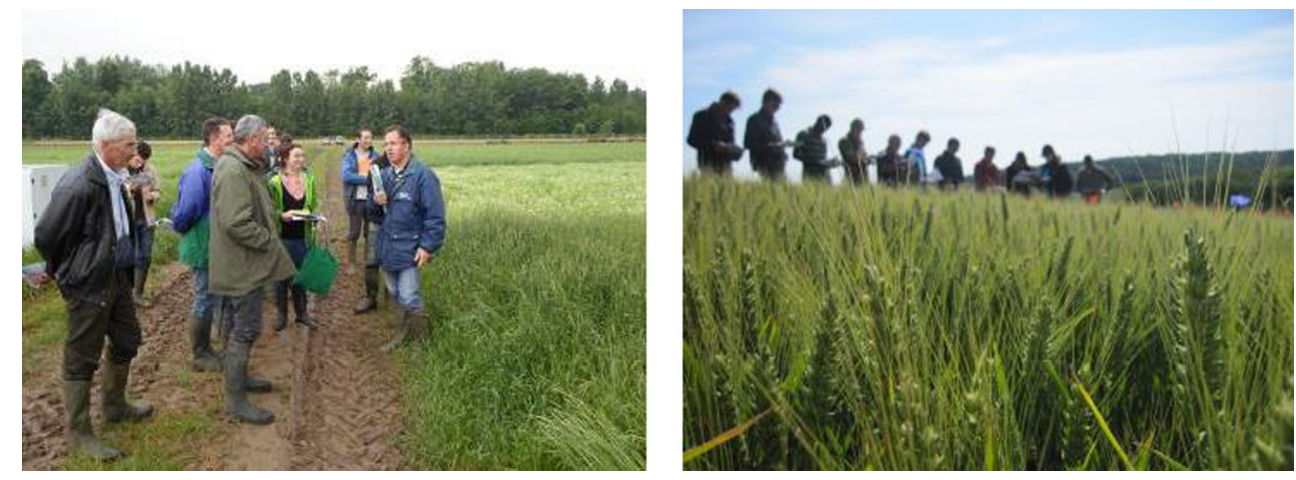


\section{Results and discussion}

In all the case studies together, we identified 260 statements corresponding to indicators. A large majority was provided by the interviews (117 from simple interviews, 107 from the retrospective analysis of the redesign project) compared to other sources ( 13 from the farmers meetings, 23 from the visits of system trials).

\subsection{Functions fulfilled by indicators for farmers' action}

\subsubsection{Identification of 22 functions sorted into 5 categories}

Among the 260 statements of indicators, we distinguished 22 functions grouped into 5 categories (Table 2):

1. The choice of a technique (e.g., selection of varieties, choice between two crop management plans): this consisted of two distinct functions concerning the tactical level: compare technical options (1) and identify the characteristics of an initial situation (like soil properties) to adapt the technical choice (2). These functions corresponded to indicators used in a preparatory step for the implementation of a new action.

2 . The adaptation-monitoring of ongoing action: indicators were mainly applied at the operational level in order to refine a modality of action (3); determine optimal conditions for the application of the chosen technique (4); trigger the action (5); and identify an ongoing dynamic to adapt the action (6). We also identified a function at the tactical level: identify a key stage in a crop management plan in order to reach an objective (7).

3. The verification of the expected effect and diagnosis of viability of an action or technique never implemented previously. Three functions concerned the operational level: know that the expected action has been performed (8); validate the fact that an intermediate state of the system was reached when such a state was previously identified by the farmer in past experience (9); and verify the effectiveness of the action (10). Other functions concerned the tactical and strategic levels: verify the viability of a technique (11) and interpret the viability of a strategic choice (12).

4. The anticipation of a system's evolution or of a result: This category encompassed functions at all three decision levels. Hence, expectations concerned widely diverse time scales, from a few weeks to several years. At operational level, it was to anticipate a system's evolution in the short-term (13) and assess a potential to provide a specific function (14). At the tactical level, it was to identify an intermediate state of the system considered necessary in order to achieve a result (15). Finally, at the strategic level, functions were to identify a longterm direction for the system's development (16) and know that the system remains in manageable states (17).
5. The understanding-reinterpretation either of a functioning of natural processes and biological regulations or the potential effects of the action on these processes. In this category, functions were to identify an ongoing dynamic to reinterpret a strategic choice (18); identify an intermediary state of the system to reinterpret a posteriori the effects of an action (19) (this corresponds to the identification of a specific state of the plant, field, or ecosystem that the farmer cannot explain yet but keeps in mind for later interpretation); reinterpret the effect of action (20); identify a biophysical causeeffect link (21); and identify a strategic cause-effect link (22) (the term "strategic" refers here to combinations of practices motivated by a same agronomic principle). Examples of indicators and the associated excerpts are presented in Table 3.

The functions that indicators fulfill in the course of a farmer's action are seldom discussed in the agronomic literature, but we found consistency between the typology we proposed and a few others, in agronomy and other domains (environment management, ecology). Bockstaller et al. (2008) proposed a list of objectives set when designing new indicators, including "ex ante evaluation of actions in a planning phase; ex post evaluation of an action at the end or during its implementation; monitoring purposes with an alert function; decision support in real time to drive the system; and communication". These categories are refined in our first three categories. But, they are focused on evaluation, whereas we enlarged the functions of indicators so that they are not only normative but also provide descriptive elements to support action. This is consistent with Heink and Kowarik (2010) who separate normative indicators (including evaluative and prescriptive functions) from descriptive indicators, but there again without taking a point of view focused on the farmer's action. Our last two categories of functions (anticipation and understanding-reinterpretation) are therefore the most explicitly related to actions whose effects largely depend on local conditions and are incompletely known - which might explain why they were seldom identified in the literature. A counter example can be found in Meynard et al. (1997), who specified indicators' functions in the case of a tool supporting the monitoring of nitrogen fertilization. By showing that a function of the indicator was to "access fertilizer strategy a posteriori: [that] may lead to rectification the following year according to the rules adopted for nutrient application planning", they added a learning dimension to the indicators' functions, which can be likened to the functions of category $\mathrm{v}(18$, 19, 20, 21, and 22). 
Table 2 The 22 functions of indicators identified

\begin{tabular}{|c|c|c|c|c|c|c|c|c|}
\hline \multirow[t]{2}{*}{ Categories of functions } & \multirow[t]{2}{*}{ Decision levels } & & \multirow[t]{2}{*}{ Functions } & \multirow[t]{2}{*}{$\mathrm{Nb}$. } & \multicolumn{3}{|c|}{ steps in change } & \multirow{2}{*}{$\begin{array}{l}\text { Nb. per } \\
\text { category }\end{array}$} \\
\hline & & & & & 1 & 2 & 3 & \\
\hline \multirow[t]{3}{*}{ (i) Choice } & Tactical & 1 & Comparing technical options & 9 & $\mathrm{X}$ & & & \multirow[t]{3}{*}{41} \\
\hline & \multirow[t]{2}{*}{ Tactical } & \multirow[t]{2}{*}{2} & $\begin{array}{l}\text { Identifying features of an initial } \\
\text { situation to adapt a technical choice }\end{array}$ & 32 & $\mathrm{X}$ & & & \\
\hline & & & Total in this category & 41 & & & & \\
\hline \multirow[t]{6}{*}{ (ii) Adaptation-monitoring } & Operational & 2 & Refining a modality of action & 16 & $\mathrm{X}$ & $\mathrm{X}$ & & \multirow[t]{6}{*}{92} \\
\hline & Operational & 4 & $\begin{array}{l}\text { Determining the optimal conditions } \\
\text { for application of a technique }\end{array}$ & 20 & $\mathrm{X}$ & $X$ & & \\
\hline & Operational & 5 & Triggering the action & 29 & $\mathrm{X}$ & $\mathrm{X}$ & & \\
\hline & Operational & 6 & $\begin{array}{l}\text { Identifying an ongoing dynamic } \\
\text { to adapt the action }\end{array}$ & 33 & $\mathrm{X}$ & $\mathrm{X}$ & & \\
\hline & \multirow[t]{2}{*}{ Tactical } & \multirow[t]{2}{*}{7} & $\begin{array}{l}\text { Identifying a key step in crop } \\
\text { management to reach a goal }\end{array}$ & 14 & & $X$ & $\mathrm{X}$ & \\
\hline & & & Total in this category & 112 & & & & \\
\hline \multirow[t]{6}{*}{ (iii) Verification-diagnosis } & Operational & 8 & $\begin{array}{l}\text { Knowing that expected actions } \\
\text { have been performed }\end{array}$ & 13 & & $\mathrm{X}$ & & \multirow[t]{6}{*}{74} \\
\hline & Operational & 9 & $\begin{array}{l}\text { Validating that an intermediate state } \\
\text { of the system is reached }\end{array}$ & 10 & & $\mathrm{X}$ & & \\
\hline & Operational & 10 & Verifying the effectiveness of the action & 27 & & $\mathrm{X}$ & & \\
\hline & Tactical & 11 & Verifying the viability of a technique & 21 & & $\mathrm{X}$ & & \\
\hline & \multirow[t]{2}{*}{ Strategic } & \multirow[t]{2}{*}{12} & Interpreting the viability of a strategic choice & 18 & & & $\mathrm{X}$ & \\
\hline & & & Total in this category & 89 & & & & \\
\hline \multirow[t]{6}{*}{ (iv) Anticipation } & Operational & 13 & Anticipating an evolution of the system & 6 & $\mathrm{X}$ & $\mathrm{X}$ & & \multirow[t]{6}{*}{54} \\
\hline & Operational & 14 & Assessing a potential to provide a specific function & 12 & & $\mathrm{X}$ & & \\
\hline & Tactical & 15 & $\begin{array}{l}\text { Identifying an intermediate state of the } \\
\text { system necessary to achieve a result }\end{array}$ & 15 & & $\mathrm{X}$ & & \\
\hline & Strategic & 16 & $\begin{array}{l}\text { Identifying a direction in the evolution } \\
\text { of the system }\end{array}$ & 20 & $\mathrm{X}$ & $\mathrm{X}$ & $\mathrm{X}$ & \\
\hline & \multirow[t]{2}{*}{ Strategic } & \multirow[t]{2}{*}{17} & $\begin{array}{l}\text { Knowing that the system remains in } \\
\text { (situations) states that one knows } \\
\text { how to manage }\end{array}$ & 9 & $\mathrm{X}$ & $\mathrm{X}$ & $\mathrm{X}$ & \\
\hline & & & Total in this category & 62 & & & & \\
\hline \multirow[t]{6}{*}{ (v) Understanding-reinterpretation } & Strategic & 18 & $\begin{array}{l}\text { Identifying an ongoing dynamic to reinterpret a } \\
\text { strategic choice }\end{array}$ & 17 & & & $\mathrm{X}$ & \multirow[t]{6}{*}{107} \\
\hline & Tactical & 19 & $\begin{array}{l}\text { Identifying an intermediary state of the system to } \\
\text { reinterpret the effects of action a posteriori }\end{array}$ & 18 & & $X$ & $\mathrm{X}$ & \\
\hline & Operational & 20 & Reinterpreting the effect of action & 36 & & $\mathrm{X}$ & & \\
\hline & Operational & 21 & Identifying a biophysical cause-effect link & 58 & & $\mathrm{X}$ & \multirow{3}{*}{$X$} & \\
\hline & \multirow[t]{2}{*}{ Strategic } & \multirow[t]{2}{*}{22} & Identifying a strategic cause-effect link & 14 & & & & \\
\hline & & & Total in this category & 143 & & & & \\
\hline
\end{tabular}

They are grouped in five categories: (i) choice, (ii) adaptation-monitoring, (iii) verification-diagnosis, (iv) anticipation, and (v) understanding-reinterpretation. The column " $\mathrm{Nb}$ " counts the number of indicator statements (identified in excerpts) which correspond to each function. The column "Nb. per category" counts the same for each category of functions (this figure is smaller than the intermediary totals in column Nb, showing that same statements often play two different functions in the same category). The different functions are also associated with the successive steps in technical changes: " 1 " for choice of the technique, decision to apply it, preparation for implementation; "2" for tests, adaptation of specific monitoring of action, stabilization of operational method; and " 3 " for evaluation of consequences on the system, other related and/or necessary changes. Finally, decision levels are displayed

The functions identified in the literature therefore relate to different scales and points of view (for instance, sometimes defined according to the farmers' activity, sometimes according to the necessity to monitor impacts of farmers' action on an environment possibly managed by others), which prevented us from building a complete conceptual framework. Our typology makes it possible to identify clearly the functions taken into account for farmers' actions and complements them with a dynamic approach to technical change. 
Table 3 Examples of indicators for each function identified

Functions Examples

1 Comparing technical options

2 Identifying features of an initial situation to adapt a technical choice

3 Refining a modality of action

4 Determining the optimal conditions for application

5 Triggering the action

6 Identifying an ongoing dynamic to adapt the action

7 Identifying a key step in crop management to reach a goal

8 Knowing that expected actions have been performed

9 Validating that intermediate state of system is reached

10 Verifying the effectiveness of the action

11 Verifying the viability of a technique

12 Interpreting the viability of a strategic choice

13 Anticipating an evolution of the system

14 Assessing a potential to provide a specific function

15 Identifying an intermediate state of the system necessary to achieve a result

16 Identifying a direction of the system's evolution
Visual weed pressure on the following crop to compare the weeding effect of two crops: "It is either rye or triticale, and I observed, there's no doubt, in the triticale field weeds appeared, the crop was a bit weak, whereas the rye cleaned the plot and you know what, after a month it was obvious, you could see the part... you could still could see the precrop effect of rye."

Dominant weed species on a plot: "You have to know your own plot, what dominant weed flora is present in the plot, what problematic weeds. [...] If the plot presents such or such a weed that bothers me, I try to choose my crops according to them."

Destruction rate of a permanent alfalfa cover before wheat sowing: "discussing with P.T., it's only there that I had partial answers. He said that at least $50 \%$ of the alfalfa had to be destroyed."

Climate during the days following mechanical weeding: "You've got to have the right weather conditions afterwards, you need to have a dry day for it to be efficient."

Date-plant stage-aphids presence combination for triggering an insecticide spraying: "On oilseed rape, aphids in the fall, we know that until such a date and such a stage it you have to be vigilant. I check beforehand, I go to see my oilseed rape at the two-leaf stage, I look, no aphids, I drop it. If at 4-leaves there are aphids, they have exceeded the stage, I don't treat them anymore."

Carabids presence to decide whether to treat for slugs or not: "And a plot that I'd taken over, man, I had sown rapeseed, and then I noticed that there were ground beetles, ah I said, this plot'll be okay, there are lots of beetles. I had fewer ground beetles, and then I went away for two or three days. And when I got back all the rapeseed had been eaten..."

A calculated indicator for weed pressure in crop succession: "For instance, if the fact of doing a false seed bed at a specific moment, it's very important for the risk of weed pressure not to rise, to stay low, for instance."

Seedbed state after direct sowing: "And since things turned out very badly, there were a lot of seeds on the surface [...] I said okay, too bad, I gave up the idea of doing the whole plot, so I hitched the plough."

Threshold in rape plant density: "There are thresholds, my rape's missing so many plants, whether it branches or not, in any case it lacks plants so it's penalized automatically."

Percentage of weeds eliminated by a mechanical weeding: "For me it was I have weeds that are there, I want to get rid of them, I believe that if I've still got that percentage compared to what there is, I'll be happy."

Growth of the crop after a green manure: "Until now I haven't evaluated it until the yield, but yes in the growth spurt at the beginning it shows. Afterwards, in its performance, it is possible, it's true that this year the spring crops were superb, and there had been a prior green manure, and they were really good. But there may also be a season effect."

TFI evolution over several years, compared among farmers in a group: "I did so much that now I'm starting to increase in the herbicides again"; "Otherwise, we were talking to thin air. Whereas there it was more on overall strategies, all that, we realized how things evolved over the years."

Crop population structure (density, vigor) to anticipate diseases' development: “Anyway the diseases will always appear where your plant is a bit weak. This is where it first breaks out. Yeah but for diseases there is also the density which is also really important. Density, biomass. With a high biomass high humidity at the field level diseases tend to develop more."

Cover crop structure to assess the covering of soil: "It's true that I saw what it gave in terms of volume, it is true that it covered the ground very well. We saw that there was different vegetation on different levels of coverage."

Position of the pea flowers in the crop stand which corresponds to good vigor: "Anyway peas are easy, as soon as you see the flowers that emerge, it's not good, the flowers should be inside. As soon as you see the flowers appear on the surface you're done for. Even a plot of this color there, the flowers should be like this, inside."

Yield stagnation when implementing a new crop sequence: "I realize very quickly the limits of the system, because the yields are capped, I see the need to use more pesticides, and also to spray a lot." 
Table 3 (continued)

Functions Examples

17 Knowing that the system remains in (situations) states that one knows how to manage

18 Identifying an ongoing dynamic to reinterpret a strategic choice

19 Identifying an intermediary state of the system to reinterpret the effects of action a posteriori

20 Reinterpreting the effect of action

21 Identifying a biophysical cause-effect link

22 Identifying a strategic cause-effect link
A 3-year forecast of a calculated risk of weed pressure: "Because it's there too, which was interesting, you'd see that in that year you'd have quite a high risk for those weeds, but as your rotation happened afterwards with other impacts, you were aware that the following year or two years later your risk was not increasing, it was even decreasing, although there was no herbicide treatment."

Thistle pressure dynamic in a specific crop sequence: "Within two years, in the seed-crop, in the time it took to grow the wheat, we had the first thistles coming up and in the seedcrop we already had the first patches."

Crop structure when sown densely: "We sowed densely, so we ended up having fragile stems, so we put in a growth regulator because they grew towards the light so it was frayed like that, we put in a growth regulator to have them like that, we put in lots of nitrogen, so that whole pattern."

Wheat regrowth after rotative harrow weeding: "But three days later everything started to grow and it was on the way again, because in fact the rotating harrow, the roots of wheat are much stronger at this stage than the roots of the weeds, so the weeds are ripped because they are at the white filament stage."

Neutrophil weed fragility caused by localized $\mathrm{N}$ fertilization: "And I have the feeling that nitrophilous plants, not having any nitrogen between the rows, were more prone to weed control. I don't mean that because there was less nitrogen they didn't grow, they grew the same, it's the same."

Comparison of treatments applied on strips with different crop management strategies: "We were doing our usual crop management, which was often advised by cooperatives, or a development group, and then next to what we put in integrated management, and then we left control strips. And when we saw that we were coming up almost to heading and that there was no disease in our control strips and that conventional crop management was already onto its fourth fungicide, there was clearly something wrong."

\subsubsection{Quantitative analysis: an extensive use of the indicators for farmers to build a reflexive understanding of their own practices and agronomic reasoning}

The individual functions most frequently encountered were functions $21 \quad(n=58$ statements), $20 \quad(n=36), 6 \quad(n=33), 5$ $(n=29)$, and $10(n=27)$. Whereas functions 5 (triggering the action) and 10 (verify the effectiveness of the action) corresponded to well-known functions in the literature, the others $(6,20,21)$ were newly identified. Like most other functions (17/22), they corresponded to indicators used in the second step of technical change (Table 2). This step corresponds to the first implementations of new techniques. It is defined as an adaptation phase of the specific management and monitoring of a practice to the local situation. It thus requires farmers to identify the expected or potential effects of new actions and, accordingly, to refine the modalities of action. Among the five categories of functions, the adaptation-monitoring (ii), and the understanding-reinterpretation (v) categories were used most (92 and 107 statements respectively out of 260), whereas most of the indicators produced in agronomy have been designed to assess the overall performance and the impacts of cropping systems, which would correspond to our categories "verification-diagnosis" (iii) or "anticipation" (iv), which are represented far less. The predominance of category (v), "understanding-reinterpretation", matches the fact that farmers question their own reasoning, which evolves with their management of agroecosystems. Some studies have also described a learning function of indicators (e.g., Wustenberghs et al. 2012; Marchand et al. 2014), exploring farmers' approach and understanding of sustainability and sustainable farming. Wustenberghs et al. (2012) mention that discussions based on indicators "can lead to changes in attitudes, norms, perception, and behavior." We have underlined the importance of indicators for the reflexive approach and evolution of the agronomic reasoning that farmers associate with their own practices.

Surprisingly, we could not clearly identify a function corresponding to an early warning for an unwanted trend of the system, often mentioned in the literature (e.g., Fränzle 2006; Barrios et al. 2006). We did however distinguish different functions concerning long-term dynamics which can be related to warning functions and which matched descriptions of long-term indicators in previous studies (e.g., Dalgaard et al. 2012). These were mostly functions (16) and (17). Actually, in our case studies, farmers implemented some practices they 
had never experimented with before: they often did not know which immediate action is needed to be taken following a warning signal. Nonetheless, they were intently modifying their system, aware that some unexpected changes might occur. They were thus ready to reinterpret their actions $a$ posteriori and to adapt their future decisions accordingly.

To sum up, the framework of functions we built clearly emphasizes the need to consider the adaptation-monitoring, understanding-reinterpretation functions of indicators, which can be termed "learning functions," during technical changes involving natural processes and innovative techniques. In fact, these learning functions were quantitatively dominant in our study.

\subsection{Attributes of indicators}

\subsubsection{Six categories of attributes identified}

The first output of our analysis of the attributes of indicators was the identification of six main categories of descriptions, including two to five modalities (Table 4). We distinguished indicators according to their nature: visual, physical-chemical feature, calculated, or measured. The "visual" attribute, by contrast with the "calculated" and "measured" ones, corresponds to information deduced from non-instrumented observations. It can correspond to quantitative information but mostly refers to a relative reference framework. We then distinguished the indicators according to their form: binary, relative, quantified in absolute terms, in reference to an initial situation, or in reference to a value in a group of farmers. A binary indicator is a variable which takes only two different values, such as the presence or absence of different populations (pests, natural enemies), without the need to quantify them. Farmers' comments about such binary indicators highlighted their objectivity and their easy and robust interpretation. We then distinguished indicators according to their time scale, that is, the period concerned by the information collected: multiyear -2 or 3 years running, e.g., concerning pre-crop effects, time scale of the object of action, information acquired subsequent to the action, e.g., effect of a specific crop deduced from the state of a plot during the following crop growth, long-term evolution-relating to evolutions spread over more than 2 or 3 years or to trends that cannot be noticed from one year to another. We then distinguished the indicators according to the spatial scale of the following: the object of the action, objects other than the one targeted through the action, the field, and the farm. In both time and spatial scales, we used the item "object of action." This corresponds to the agronomic objects that are directly manipulated by the farmer and are at the center of attention during the technical change (e.g., the crops themselves when new crops are being introduced or the weed populations when the crop sequence and management are being adapted to control weed pressure). We then distinguished the indicators according to their mode of acquisition (Fränzle 2006): "active," when instrumentation or specific management is intentional (e.g., the double-density sown strip), or "passive," meaning that spontaneous phenomena are observed without other means than the farmers' own body. We finally distinguished the indicators according to their frequency of assessment (static, repetitive). These attributes are summed-up in Table 4.

\subsubsection{Quantitative analysis: passive, visual, and relative indicators are dominant to support the design of technical changes}

Of all the indicators identified, some modalities were predominant in each category of attributes (Table 4). Most indicators were visual $(63 \%)$ (examples are displayed in Table 4); the calculated $(5 \%)$ and measured $(27 \%)$ indicators were mentioned in surprisingly low proportions. Whereas most of the indicators produced by agronomists are quantitative (Gras 1989), it has been pointed out several times that visual indicators are also relevant (e.g., Mairura et al. 2007), particularly in relation to bioindicators in ecology (Heink and Kowarik 2010). Second, the indicators were predominantly in a relative form (62\%), notably because $87 \%$ of visual indicators are relative. What we call relative indicators acknowledges that the reference itself may be in a relative form or defined in relation to other variables (e.g., in intercrop, height of alfalfa relative to wheat, to trigger an action). Relative indicators were either not quantifiable or interpreted in rough terms and without figures. although they were related to quantities. This was at the expense of quantified $(29 \%)$ or binary $(8 \%)$ indicators. Third, most of the indicators were at the time scale of the object of the action (58\%), whereas indicators that were multiyear, longterm, and subsequent to the action were found in comparable proportions (19, 12, and $11 \%$ respectively). Fourth, concerning spatial scales, modalities were more distributed, with a slight majority at the plot scale (45\%), and $25 \%$ of the indicators focused on the object of action. The relevance of such scales for action has already been discussed by Duru (2013), who underlined that the indicator of sward height on grazed fields, at paddocks scale, is "unsuitable for managing pastures over a grazing season because they cannot indicate grazing efficiency at the farm level". Our contradictory analysis may be tempered by the fact that we confirm that all possible spatial scales are taken into account. A relatively high proportion of indicators concerned objects other than those directly targeted by the action $(29 \%)$. Fifth, the passive indicators were largely predominant (75\%) compared with active indicators. Finally, we identified that $30 \%$ of the indicators concerned tendencies observed either in the short-term or over several years.

To sum up, it appears that the combination of dominant attributes corresponds to visual, relative, passive, and static indicators on the time scale of the object of action and the plot 
Table 4 Presentation of the framework of attributes

\begin{tabular}{|c|c|c|c|}
\hline \multicolumn{2}{|l|}{ Attributes } & \multirow[t]{2}{*}{ Prop. $(\%)$} & \multirow[t]{2}{*}{ Examples } \\
\hline Categories & Modalities & & \\
\hline \multirow[t]{4}{*}{ Nature } & Visual & 63 & $\begin{array}{l}\text { Plant stand structure (soil cover, density, relative height); crop color changes; } \\
\text { plant (crop, weed) development stage; wheat lodging; direct adjacent environment of a plot. }\end{array}$ \\
\hline & Phy-chem. char. & 5 & Soil characteristics (stoniness, porosity, humidity, etc.) \\
\hline & Calculation & 5 & Treatment frequency index (TFI); number of days between harvest and stubble ploughing. \\
\hline & Measure & 27 & Number of stems per square meter; yields; depth of soil tillage \\
\hline \multirow[t]{5}{*}{ Form } & Binary & 8 & Existence of wheat lodging; presence of natural pest enemies \\
\hline & Relative & 62 & $\begin{array}{l}\text { Relative height of crop and weeds; plant stand structure and soil cover; weed pressure; } \\
\text { crop growth dynamic }\end{array}$ \\
\hline & Quantitative abs. & 17 & Number of stems per square meter; end date for cover crop sowing \\
\hline & Quanti./group & 4 & Yield; number of herbicide treatments; stubble plough depth \\
\hline & Quanti./initial sit. & 9 & Yield evolution; soil organic matter content evolution \\
\hline \multirow[t]{4}{*}{ Time scale } & Multiyear & 19 & 3 -year forecast of a calculated weed pressure risk \\
\hline & Object of action & 58 & Crop stage; disease development; discoloration of double density strips \\
\hline & Subsequently & 11 & $\begin{array}{l}\text { Growth vigor of a crop following green manure; relative weed pressure on the following } \\
\text { crop; yields of the } 2 \text { or } 3 \text { following crops; weather in the days following harrowing }\end{array}$ \\
\hline & Long term & 12 & Soil characteristics; evolution of natural enemy populations; past crop successions on a plot \\
\hline \multirow[t]{4}{*}{ Spatial scale } & Object of action & 25 & Crop stage and growth dynamic; relative height of plants; weeds' state after mechanical weeding \\
\hline & Other object & 18 & Presence/absence of natural pest enemies; weeds as bioindicative plants; worm counting \\
\hline & Plot & 45 & Crop stand aspect in the spring; yield; sowing density; weeds presence; pre-crop effect of legumes \\
\hline & Farm & 12 & Treatment frequency index; microclimate \\
\hline \multirow[t]{2}{*}{ Acquisition } & Passive & 75 & $\begin{array}{l}\text { Crop growth dynamic; plant stage; presence/absence of natural pest enemies; wheat lodging; } \\
\text { dominant weed species on a plot }\end{array}$ \\
\hline & Active & 25 & Double density strips; measured depth of soil ploughing; soil organic matter content \\
\hline \multirow[t]{2}{*}{ Dynamics } & Tendency & 30 & $\begin{array}{l}\text { Yield evolution; disease progression on plant and on the plot; weed pressure calculated risk } \\
\text { over several years; weed pressure progression over the years on the same plot }\end{array}$ \\
\hline & Static & 70 & Sowing density; end date for crop sowing; weeds density thresholds for treatments \\
\hline
\end{tabular}

"Phy-chem char." stands for physical-chemical characteristics; "quantitative abs." for quantitative in absolute terms; and "quanti./group" and "quanti./ initial sit." for quantification in reference to a group mean or in reference to an initial situation on the same farm, respectively. We distinguished six categories, and from two to four modalities per category. The column "Prop." gives the percentages (among all statements analyzed) of each modality within a category. Bold modalities and italic entries correspond to the highest proportions

spatial scale. We showed that dynamic interpretations were prevalent for some indicators classically used as quantified values compared to thresholds (e.g., yields were assessed as much according to their absolute value, as according to their evolution in relation to a new strategy applied, and the weed pressure was often expressed in terms of evolution rather than of absolute quantity).

\subsection{Relations between functions and attributes of indicators}

Cross-comparing functions and attributes of indicators makes it possible to identify specific types of indicators that should be produced to equip farmers for deep technical change.

\subsubsection{Original attributes of indicators mainly correspond to functions at strategic decision levels}

There was a global stability of predominant attributes among all five categories of functions: visual, relative, and passive indicators, considered at the time of the action and at the plot scale, and static.

When focusing on the attributes that differ from the predominant profile, we find that most of them correspond to 
functions associated with the strategic decision level (functions 12, 16, 17, 18, and 22) (Table 5).

They present a larger proportion of calculated and quantified indicators, concerning either multiyear or long-term time scales. The majority was at farm scale, was active, and was observed as tendencies. Moreover, they were analyzed in combination with other types of indicators, in order to align the assessment of applying a strategy with the observations of agronomic results and the evolution of situations. For instance, the percentage of winter crops (and its trend) was aligned with the farmer's evaluation of weed pressure (on a visual scale) to interpret the possible agronomic relation. We also found cases of combinations of two indicators of farmers' practices that made it possible to reinterpret the effect of techniques and the viability of strategies. For instance, they aligned the mean dates of wheat sowing with the number of herbicide applications, calculated for each farm and several years, as a means to reinterpret the effect of the technique. They also used comparisons within the group to explain the particularities of some agronomic situations.

Indicators at this strategic level are rare in agronomy. Those identified in the literature mainly concern functions at the operational and tactical levels. Nonetheless, a few examples of indicators at strategic level can be found, corresponding for instance to the assessment of the evolution of practices at farm level or the monitoring of the system's sustainability (e.g., Marchand et al. 2014). Here, we show that the indicators designed to play functions mainly at the strategic decision level are strongly mobilized by farmers (58, that is, $22 \%$ of all statements), which may encourage agronomists to focus on them. They also need to be combined with other observations in order to reinterpret the effects of actions and identify strategic cause-effect links.

Table 5 Predominant attributes of indicators within each specific role

\begin{tabular}{|c|c|c|c|c|c|c|c|c|}
\hline \multicolumn{3}{|c|}{ Functions } & \multicolumn{6}{|l|}{ Attributes } \\
\hline & & & Nature & Form & Time scale & Spatial scale & Acquisition & Dynamic \\
\hline \multirow[t]{2}{*}{ (i) } & $\mathrm{t}$ & 1 & Visual & Relative & Object of action & Plot & Active & Static \\
\hline & $\mathrm{t}$ & 2 & Visual & Relative & Long term & Plot & Passive & Static \\
\hline \multirow[t]{5}{*}{ (ii) } & o & 3 & Measure & Quantified absolute & Object of action & Object of action & Passive & Static \\
\hline & o & 4 & Visual & Relative & Object of action & Plot & Passive & Static \\
\hline & o & 5 & Visual & Relative & Object of action & Plot & Passive & Static \\
\hline & o & 6 & Visual & Relative & Object of action & Plot & Passive & Tendency \\
\hline & $\mathrm{t}$ & 7 & Visual, measure & Relative & Subsequently to object & Plot & Passive & Static \\
\hline \multirow[t]{5}{*}{ (iii) } & o & 8 & Measure & Quantified absolute & Object of action & Object of action, plot & Passive & Static \\
\hline & o & 9 & Visual & Relative & Object of action & Plot & Passive & Static \\
\hline & o & 10 & Visual & Relative & Object of action & Plot & Passive & Static \\
\hline & $\mathrm{t}$ & 11 & Measure & Relative, quanti./initial & Object of action & Plot & Passive & Static \\
\hline & $\mathbf{s}$ & 12 & Visual, calcul & Relative, quanti./group & Multiyear, long-term & Farm & Active & Tendency \\
\hline \multirow[t]{5}{*}{ (iv) } & o & 13 & Visual & Relative & Object of action & Object of action & Passive & Tendency \\
\hline & o & 14 & Visual & Relative & Object of action & Object of action, other obj. & Passive & Static \\
\hline & $\mathrm{t}$ & 15 & Visual & Relative & Object of action & Plot & Passive & Static \\
\hline & $\mathbf{s}$ & 16 & Visual, calcul & Relative, quanti./initial & Multiyear & Farm & Active & Tendency \\
\hline & $\mathbf{s}$ & 17 & Visual, calcul & Relative, quanti. abs./initial & Multiyear & Plot, farm & Passive & Tendency \\
\hline \multirow[t]{5}{*}{ (v) } & $\mathbf{s}$ & 18 & Visual & Relative & Object of action, multiyear & Other object & Passive & Tendency \\
\hline & $\mathrm{t}$ & 19 & Visual & Relative & Object of action & Plot & Passive & Static \\
\hline & o & 20 & Visual & Relative & Object of action & Plot & Passive & Static \\
\hline & o & 21 & Visual & Relative & Object of action & Other object & Passive & Static \\
\hline & $\mathbf{s}$ & 22 & Measure & Relative, quanti./group & Multiyear & Farm & Active & Tendency \\
\hline
\end{tabular}

“quanti. abs.," "quanti./initial," and "quanti./group" stands respectively for quantification in absolute terms, in reference to a group, in reference to an initial situation on the same farm

In the left end column, brackets refer to the categories of role; letters correspond to the levels of decision (o: operational, t: tactical, s: strategic); the number refers to the number of the individual roles. We have emphasized in italics the predominant attributes that differ from a general profile and bold and bolditalic the observed characteristics of indicators concerning the strategic level 


\subsubsection{A robust framework that points to new indicators to develop}

From a variety of case studies, we identified the functions and attributes of indicators that are used throughout the implementation of technical changes during redesign processes. These frameworks of attributes and functions allowed us to represent the diversity of the indicators encountered. This suggests that the frameworks are robust enough to be reused in other cases even if the distribution of indicators within these frameworks would certainly vary with other types of production system redesign (e.g., with a predominantly livestock system). The major functions and attributes provide useful guidelines for agronomists to develop new indicators that make redesign processes possible and that support them.

From the function analysis, we showed that indicators are needed primarily for learning purposes rather than for assessment and evaluation purposes only. These learning functions seem necessary so that farmers can connect technical changes to the rest of their cropping system: "We are working with life forms. How do we know that at some point we've improved or worsened a situation? We don't know, we know at the end of the year when we've harvested, but we know in relation to a yield; what about compared to something else? What about the soil life, the weeds, natural pest enemies, have we improved or worsened the situation? We don't know anything. [...] we're in a total haze," (a farmer). Learning functions corresponded to all three decision levels that we distinguished. In fact, they concerned farmer's action per se as much as all the possible consequences of that action, and the biophysical processes and causal relations that are impacted by it or that explain its results.

Based on the attribute analysis, we have shown that the indicators corresponding to these learning functions are mainly visual, relative, on the time scale of the object targeted by the action, and static. All these attributes are original compared with those reported in the literature. The visual nature of indicators has sometimes been acknowledged in the literature (e.g., Mairura et al. 2007, who underscore "the value of taking into consideration the visual and morphological soil characteristics used by farmers" but mainly for the assessment of characteristics such as soil fertility. The spatial scales of learning indicators show more diversity, as they concern objects other than those directly relevant to the action (e.g., the following crop, bioindicative weeds, natural pest enemies not considered in technique planning). This has seldom been noted in the literature, except for bioindicative weeds. Murage et al. (2000), for instance, pointed out that "farmers reported that the red top grass appears after long-term cultivation that has resulted in infertile and compacted soils." Finally, these indicators are mostly passive. Whereas this is common for ecological indicators, namely in the case of bioindication (Dziock et al. 2006), active indicators are predominant in agronomists' production: e.g., Nitrogen Nutrition Index (Prost and Jeuffroy 2007), soil mineral N content at the end of winter, and double-density sowing strip for nitrogen fertilization monitoring, developed on scientific bases proposed by Limaux et al. (1999). Our study shows that passive indicators provide a necessary focus in a situation (e.g., on certain plants' or pests' presence, on morphological states of cultivated crops, on soil aspects) associated with the related knowledge on these objects or their relations and any related actions.

Whatever the functions of indicators, other specific and original attributes were found for those indicators related to a strategic decision level, which account for a large proportion of the indicators mentioned by farmers. These indicators are notably more dynamic: the information collected corresponds to tendencies. By contrast, indicators produced by agronomists are mainly static: data are collected at a specific time to evaluate a result, even if it aggregates a whole dynamic on the growth time of a crop. This was already pointed out concerning the comparative analysis of agroecosystems (Doré et al. 2011) and was discussed by Connoly et al. (2001), for instance, in the case of intercrops: indicators of competition within the species mixture are mainly based on a final result, whereas one might need to consider the dynamic aspect of competition during the growth period to evaluate the actual competitive strength of species and to be able to design appropriate mixtures. The same observation was made by Duru (2013), who mentioned studies of grassland plant composition as a function of management and environment that "portray grasslands statically, and [the fact that] usually stakeholders cannot easily manipulate the management variables or indicators used to predict or describe grassland composition, respectively". Our observations support the mobilization of indicators which may already be used statically but with a dynamic approach. This is consistent with what, for instance, Casagrande et al. (2012) proposed in the case of organic wheat production, that is, that the early "weed density dynamic seems to be a good indicator of weed pressure on grain yield."

\subsection{Consistency of the identified indicators with an adaptive management approach}

We found that a large proportion of the indicators supported functions related to the adaptation-monitoring of new actions, the effects of which are partly unknown. This is consistent with an adaptive management approach. Originally developed in the field of environment management, the adaptive management paradigm insists on the necessity of monitoring the effects of actions throughout the evolution of the ecosystem (e.g., Clark 2002). We could not find sufficiently accurate characterizations of the indicators involved in such monitoring to be able to deduce implications concerning the indicators that agronomists would have to produce to equip these types of actions. Nevertheless, several elements corroborate our 
conclusions. For instance, according to Clark (2002), “adaptive management also encompasses a more process-orientated view of management, whereby a valid aim of management is engagement in a satisfying and satisfactory process rather than just achieving a specific outcome." This corresponds to the main functions of indicators that we identified, focused more on the necessary management of a process than on the precise results to obtain.

Adaptive management also recognizes the learning purpose of such monitoring (Westgate et al. 2013). We identified functions related to the learning process that occurs through the retrospective analysis of action. Associated with the identification of dynamics in the system and in intermediary states, the indicators corresponding to these functions were either observations made without the capacity to interpret directly (function 19) or identifications of a known necessary state of the system to obtain certain results (function 15). They were also indicators that made it possible to identify biophysical cause-effect links (function 21) in the biological regulation of the agroecosystem, as well as the resulting interpretation logics of the indicators themselves. Nevertheless, rather than looking for specific, limited attributes of indicators which facilitate learning and reinterpretation, we identified various successive uses of different indicators as learning processes. For instance, the depth of stubble plowing was combined with the dynamic observation of another object, subsequent to the action (following wheat on the same plot) to reinterpret the effect of action. It was also related to the observation of the possibility to apply other practices (e.g., based on the behavior of a machine on the plot).

\section{Conclusion}

In this article, we have presented a characterization of functions and attributes of indicators used by farmers engaged in redesigning their cropping systems and have shown that these indicators do not match those that are classically produced in agronomy. Rather than making proposals to improve the quality and reliability of existing indicators, our results argue strongly for the development of new types of indicators. In fact, we reveal the acute need for indicators that make it possible not only to verify and diagnose the direct effects of new techniques implemented but also to adapt and monitor the new actions corresponding to these techniques, as well as to understand and reinterpret the functioning of related natural processes and how the previous and new practices impact them. Cross-comparing these functions with the attributes of indicators enabled us to identify mismatches between existing indicators and farmers' uses thereof. We have shown that visual and relative indicators are predominant among those mobilized by farmers through their action. More particularly, we have highlighted the fact that indicators revealing tendencies are specifically relevant to actions within a step-by-step redesign process and are necessary at a strategic decision level.

Our findings are consistent with the need to develop management support tools dedicated to evaluation and monitoring of the ongoing processes of action rather than strict assessment of precise and quantified sustainability goals achievement. As Duru (2013) noted, "tools can be used during an action to adapt practices that allow indicator thresholds to be met, by monitoring them at appropriate time scales." One might directly associate such tools with agronomic models, but our results challenge this choice. In fact, the models at the soilcrop-atmosphere interface or at cropping system level seldom include the types of indicators we identified in farmers' actions, namely indicators with qualitative references, interpreted in tendencies, or indicators based on objects other than cash crops. It may seem that we argue that the tools Duru (ibid) refers to should be based on an accurate replication of the indicators that we characterized, based on farmers actions. But, these are indicators developed by the farmers themselves, for particular and non-reproducible situations. Agronomists should not try to imitate all these indicators, but they should definitely be inspired by the relevant attributes and functions in validating, stabilizing, and generalizing new indicators: relative variables with visual references, which are directly related not to a decision rule but to the evolution of system states that may lead farmers to adapt various operations, techniques or strategies.

Acknowledgements This work was supported by the Région Ile-deFrance under a grant from DIM Astréa; and INRA under a grant from the meta-program SMaCH. We thank Liz Libbrecht for language editing the English version of this paper and are deeply grateful to the editor and the two anonymous reviewers for their help in improving it.

\section{References}

Barrios E, Delve RJ, Bekunda M et al (2006) Indicators of soil quality: a south-south development of a methodological guide for linking local and technical knowledge. Geoderma 135:248-259. doi:10.1016/ j.geoderma.2005.12.007

Bockstaller C, Guichard L, Makowski D et al (2008) Agri-environmental indicators to assess cropping and farming systems. A review. Agron Sustain Dev 28:139-149. doi:10.1051/agro:2007052

Casagrande M, Joly N, Jeuffroy M-H et al (2012) Evidence for weed quantity as the major information gathered by organic farmers for weed management. Agron Sustain Dev 32:715-726. doi:10.1007/ s13593-011-0073-6

Chantre E, Cardona A (2014) Trajectories of French field crop farmers moving toward sustainable farming practices: change, learning, and links with the advisory services. Agroecol Sustain Food Syst 38: 573-602. doi:10.1080/21683565.2013.876483

Clark MJ (2002) Dealing with uncertainty: adaptive approaches to sustainable river management. Aquat Conserv Mar Freshw Ecosyst 12: 347-363. doi:10.1002/aqc.531 
Connolly J, Goma HC, Rahim K (2001) The information content of indicators in intercropping research. Agric Ecosyst Environ 87: 191-207. doi:10.1016/S0167-8809(01)00278-X

Coquil X, Fiorelli J-L, Blouet A, Mignolet C (2014) Experiencing organic mixed crop dairy systems: a step-by-step design centred on a longterm experiment. In: Bellon S, Penvern S (eds) Organic Farming, Prototype for Sustainable Agricultures. Springer Netherlands, pp 201-217. doi:10.1007/978-94-007-7927-3

Dalgaard T, Bienkowski JF, Bleeker A et al (2012) Farm nitrogen balances in six European landscapes as an indicator for nitrogen losses and basis for improved management. Biogeosciences 9:5303-5321. doi:10.5194/bg-9-5303-2012

Deffontaines J-P, Landais E (1988) Les pratiques des agriculteurs. Point de vue sur un courant nouveau de la recherche agronomique. Études Rural 109:125-158. doi:10.3406/rural.1988.3226

Doré T, Makowski D, Malézieux E et al (2011) Facing up to the paradigm of ecological intensification in agronomy: revisiting methods, concepts and knowledge. Eur J Agron 34:197-210. doi:10.1016/j.eja. 2011.02.006

Duru M (2013) Combining agroecology and management science to design field tools under high agrosystem structural or process uncertainty: Lessons from two case studies of grassland management. Agric Syst 114:84-94. doi:10.1016/j.agsy.2012.09.002

Dziock F, Henle K, Foeckler F et al (2006) Biological indicator systems in floodplains - a review. Int Rev Hydrobiol 91:271-291. doi:10.1002/ iroh.200510885

Fränzle O (2006) Complex bioindication and environmental stress assessment. Ecol Indic 6:114-136. doi:10.1016/j.ecolind.2005.08.015

Girardin P, Bockstaller C, der Werf HV (1999) Indicators: tools to evaluate the environmental impacts of farming systems. J Sustain Agric 13:5-21. doi:10.1300/J064v13n04 03

Glaser BG, Strauss AL (2009) The discovery of grounded theory: strategies for qualitative research. Transaction Publishers p 284

Gras R (1989) Le Fait technique en agronomie: activité agricole, concepts et méthodes d'étude. Editions Quae $\mathrm{p} 183$

Heink U, Kowarik I (2010) What are indicators? On the definition of indicators in ecology and environmental planning. Ecol Indic 10: 584-593. doi:10.1016/j.ecolind.2009.09.009

Horlings LG, Marsden TK (2011) Towards the real green revolution? Exploring the conceptual dimensions of a new ecological modernisation of agriculture that could "feed the world.". Glob Environ Change 21:441-452. doi:10.1016/j.gloenvcha.2011.01.004
Limaux F, Recous S, Meynard J-M, Guckert A (1999) Relationship between rate of crop growth at date of fertiliser $\mathrm{N}$ application and fate of fertiliser N applied to winter wheat. Plant Soil 214:49-59. doi:10. 1023/A:1004629511235

Mairura FS, Mugendi DN, Mwanje JI et al (2007) Integrating scientific and farmers' evaluation of soil quality indicators in Central Kenya. Geoderma 139:134-143. doi:10.1016/j.geoderma.2007.01.019

Makowski D, Tichit M, Guichard L et al (2009) Measuring the accuracy of agro-environmental indicators. J Environ Manage 90:S139S146. doi:10.1016/j.jenvman.2008.11.023

Marchand F, Debruyne L, Triste L, et al. (2014) Key characteristics for tool choice in indicator-based sustainability assessment at farm level. Ecol Soc. doi: 10.5751/ES-06876-190346

Meynard JM, Aubry C, Justes E, Bail ML (1997) Nitrogen diagnosis and decision support. In: Lemaire DG (ed) Diagnosis of the nitrogen status in crops. Springer, Berlin Heidelberg, pp 147-161. doi:10. 1007/978-3-642-60684-7

Meynard J-M, Dedieu B, Bos AP (Bram) (2012) Re-design and co-design of farming systems. An overview of methods and practices. In: Darnhofer I, Gibbon D, Dedieu B (eds) Farming Systems Research into the 21st Century: The New Dynamic. Springer Netherlands, pp 405-429. doi:10.1007/ 978-94-007-4503-2

Murage EW, Karanja NK, Smithson PC, Woomer PL (2000) Diagnostic indicators of soil quality in productive and non-productive smallholders' fields of Kenya's Central Highlands. Agric Ecosyst Environ 79:1-8. doi:10.1016/S0167-8809(99)00142-5

Prost L, Jeuffroy M-H (2007) Replacing the nitrogen nutrition index by the chlorophyll meter to assess wheat N status. Agron Sustain Dev 27:321-330. doi:10.1051/agro:2007032

Warner K (2007) Agroecology in action: extending alternative agriculture through social networks. MIT Press p 296

Westgate MJ, Likens GE, Lindenmayer DB (2013) Adaptive management of biological systems: a review. Biol Conserv 158:128-139. doi:10.1016/j.biocon.2012.08.016

Wezel A, Casagrande M, Celette F et al (2014) Agroecological practices for sustainable agriculture. A review. Agron Sustain Dev 34:1-20. doi:10.1007/s13593-013-0180-7

Wustenberghs H, Delcour I, D'Haene K et al (2012) A dual indicator set to help farms achieve more sustainable crop protection. Pest Manag Sci 68:1130-1140. doi:10.1002/ps.3332 